\title{
AVALIAÇÃO IN VITRO DO ÓLEO OBTIDO A PARTIR DA BORRA DO CAFÉ (Coffea arabica L.) COMO PROMOTOR DA PERMEAÇÃO CUTÂNEA DO METRONIDAZOL
}

\author{
Asley Thalia Medeiros Souza ${ }^{1}$, Giovana Damasceno Sousa ${ }^{1}$, Isabelle Moura Fittipaldi de \\ Souza Dantas ${ }^{1}$, Davi Pereira de Santana ${ }^{1}$ e Leila Bastos Leal ${ }^{1}$ \\ ${ }^{1}$ Universidade Federal de Pernambuco, Centro de Ciências da Saúde, Departamento de \\ Ciências Farmacêuticas, Núcleo de Desenvolvimento Farmacêutico e Cosmético \\ E-mail para contato: asleythalia_@hotmail.com
}

RESUMO - A eficácia de um tratamento tópico está diretamente relacionada à capacidade de permeação do fármaco através das barreiras cutâneas, especialmente o estrato córneo. A fim de melhorar a permeação dos fármacos através da pele, uma estratégia é a adição de promotores de permeação química. O potencial do óleo obtido a partir da borra de café como promotor da permeação de fármacos através da pele foi avaliado comparando a quantidade de metronidazol (fármaco marcador) liberada e permeada de formulações com ou sem este óleo. Para este fim, utilizou-se uma membrana sintética hidrofilica e pele de cobra da espécie Boa constrictor. Os resultados da cinética de liberação foram quantificados por espectrofotometria no ultravioleta e o ensaio de permeação foi analisado por cromatografia líquida de alta eficiência (CLAE-UV). A formulação sem óleo apresentou uma quantidade permeada de $2,05 \mu \mathrm{g} / \mathrm{cm}^{2}$, as formulações com 5 e 10\% do óleo 4,21 e 12,04 $\mu \mathrm{g} / \mathrm{cm}^{2}$, respectivamente. Tais testes indicaram que as formulações com este óleo aumentaram significativamente a permeação do metronidazol, sinalizando que o óleo da borra de café pode ser uma alternativa para promover a permeação cutânea de fármacos hidrofilicos.

Palavras chave: Óleo da borra do café. Metronidazol. Promotor de permeação.

ABSTRACT- The efficacy of a topical treatment is directly related to the permeability of the drug through cutaneous barriers, especially the stratum corneum. In order to improve the permeation of the drugs through the skin, a strategy is the addition of chemical permeation promoters. The oil potential obtained from coffee grounds as a promoter of drug permeability through the skin was evaluated by comparing the amount of metronidazole released and permeated with formulations with or without this oil. For this purpose, a hydrophilic synthetic membrane and snake skin of the species Boa constrictor were used. The results of the in vitro release test were quantified by ultraviolet spectrophotometry and the permeation assay of metronidazole was analyzed by high performance liquid chromatography (HPLC-UV). The formulation without oil presented permeated amount of 2,05 $\mu \mathrm{g} / \mathrm{cm}^{2}$, and the formulations containing 5 e 10\% of this oil 4,21 e $12,04 \mu \mathrm{g} / \mathrm{cm}^{2}$, respectively. These results indicated that the formulations with this oil significantly increased the permeation of metronidazole, signaling that the oil 
from the coffee grounds can be an alternative to promote cutaneous permeation of hydrophilic drugs.

Keywords: Spent coffee grounds oil. Metronidazole. Permeation promoter.

\section{INTRODUÇÃO}

A administração tópica é uma via alternativa à administração oral de fármacos e oferece muitas vantagens, como a ausência de efeito de primeira passagem, o fato de ser indolor e a facilidade de aplicação (SILVA et al., 2009). O Metronidazol é um derivado imidazólico com atividade antiprotozoária e antibacteriana. Pertence à classe I do Sistema de Classificação Biofarmacêutica (SCB), apresentando alta permeabilidade alta solubilidade em água. Possui lipofilicidade ( $\log$ P) de -0,1 (WAGIL et al., 2015), o que dificulta sua permeabilidade através da pele.

Muitas estratégias tem sido sugeridas para superar a baixa permeabilidade de fármacos através da pele. Uma delas foi incluir promotores de permeação em formulações. Estas substâncias reduzem reversivelmente a resistência do estrato córneo e aumentam o fluxo de penetração de moléculas através da pele (MARTINS, VEIGA, 2002).

Diversas substâncias têm sido utilizadas para este fim, incluindo terpenos e o ácido oléico (ESCRIBANO et al., 2003). Outros ácidos graxos insaturados de cadeia longa como o ácido miristoléico, palmitoléico, linoleico e linolênico, também possuem propriedades promotoras de permeação (LIMA, 2010). O óleo obtido a partir da borra de café, apresenta alto percentual de ácidos graxos insaturados, incluindo o ácido linoleico, oleico e palmítico (RIBEIRO et al., 2013), o que justifica a verificação do seu potencial em promover a permeação cutânea de fármacos.

A avaliação da liberação e permeação cutânea de fármacos, visando estimar a quantidade do mesmo que é absorvido pela pele, é realizado pelo uso de técnica in vitro, utilizando células de difusão tipo Franz. (SILVA et al., 2010). Os estudos in vitro de permeação cutânea são realizados com membranas naturais (pele humana ou animal). Podem ser utilizados como modelo natural, pele de rato, camundongo com e sem pelo, macaco rhesus, porco, cobra, entre outros (SANTIS, 2008).

Dito isto, este trabalho se propôs a avaliar o potencial do óleo obtido a partir da borra de café como promotor da permeação cutânea de fármacos hidrofílicos, utilizando como marcador o metronidazol.

\section{MATERIAIS E MÉTODOS}

A borra do café foi obtida por doação de residências e seca em 24 horas em estufa a $100^{\circ} \mathrm{C}$ para posterior extração em Soxhlet, utilizando hexano P.A como solvente, seguido de rotaevaporação para separação da mistura óleo/solvente.

A avaliação do potencial promotor de permeação foi realizada através da comparação entre a quantidade de metronidazol (MTZ) liberada e permeada das formulações de emulsões preparadas contendo, ou não, óleo da borra do café. Foram preparadas três formulações, uma sem o óleo de borra do café e duas com o óleo em diferentes concentrações, 5 e $10 \%$.

O perfil de liberação e permeação do fármaco foi definido empregando células de difusão tipo Franz automazidas. Utilizou-se membranas artificiais de acetato de celulose para a avaliação do perfil de liberação. Para avaliação da permeação cutânea in vitro, optou-se pelo emprego da pele 
de cobra da espécie Boa constrictor. Todas as formulações continham 0,75\% de MTZ e foi aplicado $100 \mathrm{mg}$ de formulação no compartimento doador da célula de difusão.

Para o estudo de liberação após cada coleta, as amostras foram quantificadas por espectrofotometria no ultravioleta em $320 \mathrm{~nm}$. Para análise do perfil de permeação das amostras foi utilizado o cromatógrafo líquido de alta eficiência (CLAE). Ambas as metodologias foram validadas segundo RE $n^{\circ}$ 899/03 da ANVISA (BRASIL, 2003).

Os dados foram tratados estatisticamente por ANOVA (Software GraphPad Prism versão 5.0) e as diferenças foram consideradas estatisticamente significativas quando $p \leq$ 0,05 .

\section{RESULTADOS E DISCUSSÃO}

É possível verificar que não houve, estatisticamente, diferença na difusão do fármaco a partir das formulações que contém ou não o óleo da borra do café (Figura 1).

Figura 1: Perfil de liberação do metronidazol in vitro

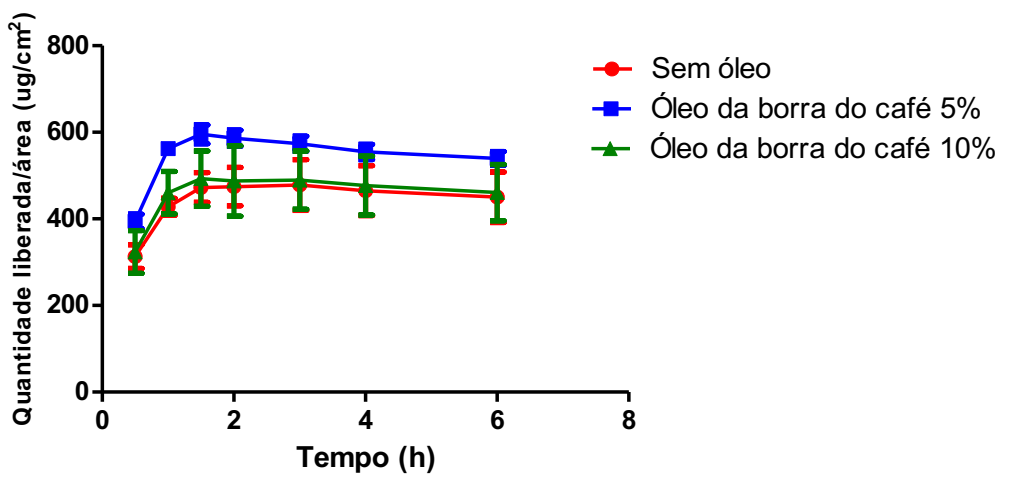

Sabendo que a viscosidade de uma formulação é um dos principais fatores que influenciam na penetração cutânea de fármacos (LIRA, 2003; WANG et al, 2001), e que não existem diferenças significativas na viscosidade destas formulações, o estudo in vitro com membrana artificial isoladamente, não é capaz de diferenciar a liberação de ambos os fármacos, em virtude de modificações sucintas nas formulações.

$\mathrm{Na}$ avaliação do perfil de permeação do metronidazol in vitro (Figura 2), houve diferença estatisticamente significativa na permeação deste fármaco a partir das formulações que contém o óleo da borra do café em relação a formulação sem óleo. Entre as formulações que contém o óleo, a formulação contendo $10 \%$ apresentou maior quantidade total de fármaco permeada, cerca de $12,04 \mu \mathrm{g} / \mathrm{cm}^{2}$, a formulação com $5 \%$, 4,21 e a formulação sem óleo, $2,05 \mu \mathrm{g} / \mathrm{cm}^{2}$.

Figura 2: Perfil de permeação do metronidazol in vitro

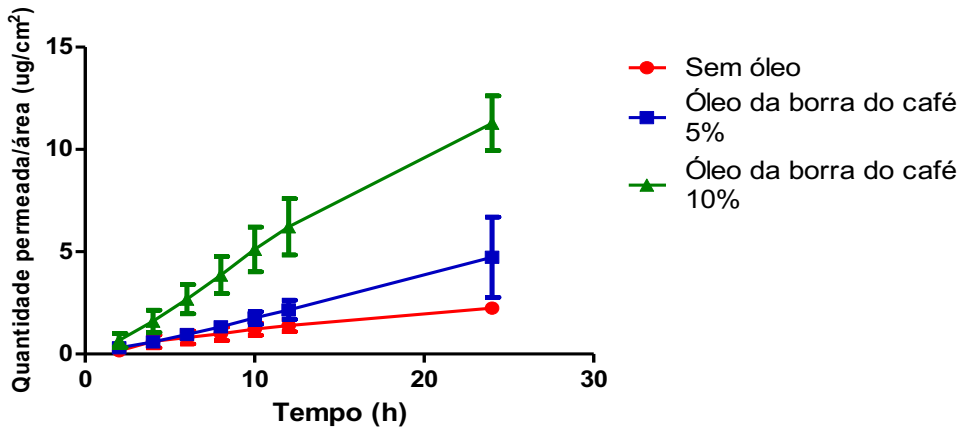


Os dados obtidos no estudo de permeação evidenciam que não só a presença, mas o aumento da concentração do óleo na formulação, promoveram o aumento da quantidade de fármaco no compartimento receptor.

\section{CONCLUSÃO}

Os resultados indicam o óleo obtido a partir da borra do café como uma promissora alternativa para promoção da permeação cutânea de fármacos hidrofílicos.

\section{REFERENCIAS}

LIMA, C. R. R. C. Identificação de ácidos graxos presentes no óleo de castanha do Brasil em emulsões cosméticas. 2010. 127f. Dissertação (Mestrado em Fármaco e medicamentos). Universidade de São Paulo, São Paulo. 2010.

LIRA, A. A. M. Estudo de Permeação In Vitro e Avaliação Térmica de Emulgel Tópico a Base de Lapachol. 2003. 81f. Dissertação (Mestrado em Ciências Farmacêuticas) - Universidade Federal de Pernambuco, Recife. 2003.

MARTINS M. R. F. M., VEIGA F. Promotores de permeação para a liberação transdérmica de fármacos: nova aplicação para as ciclodextrinas. Rev. Bras. Ciênc. Farm., v. 38, p. 33-57, 2002.

RIBEIRO, H.; MARTO, J.; RAPOSO, S.; AGAPITO, M.; ISAAC, V.; CHIARI, BG. From coffee industry waste materials to skin-friendly products with improved skin fat levels. Eur. J. Lipid Sci. Technol. v. 115, p. 330-336, 2013.

SILVA. J. A.; SANTANA, D. P.; BEDOR, D. G. C.; BORBA, V. F. C.; LIRA, A. A. M.; EGITO, E. S. T. Estudo de liberação e permeação in vitro do diclofenaco de dietilamônio em microemulsão gel-like. Quim. Nova, v.32, n. 6, p. 1389-1393, 2009.

WAGIL, M.; MASZKOWSKA, J.; BIAŁK-BIELIŃSKA, A.; CABAN, M.; STEPNOWSKI, P.; KUMIRSKA, J. Determination of Metronidazole residues in water, sediment and fish tissue samples. Chemosphere. v. 119, p.28-34, 2015.

\section{AGRADECIMENTOS}

Agradeço ao CNPq pela concessão da bolsa, à UFPE e ao NUDFAC. 